\title{
Relation between cognitive dysfunction and pseudobulbar palsy in amyotrophic lateral sclerosis
}

\begin{abstract}
S Abrahams, L H Goldstein, A Al-Chalabi, A Pickering, R G Morris, R E Passingham, D J Brooks, P N Leigh
\end{abstract}

Department of Psychology, Institute of Psychiatry, De Crespigny Park, London, SE5, UK $S$ Abrahams L H Goldstein R G Morris

Department of Clinical Neurosciences, Institute of Psychiatry and Kings' College Hospital Medical School, Denmark Hill, London, SE5, UK A Al-Chalabi P N Leigh

Department of Psychology, St George's Hospital Medical School, Cranmer Terrace, London, SW17, UK A Pickering

Department of Experimental Psychology, University of Oxford, South Parks Road, Oxford, OX1 3UD, UK R E Passingham MRC Cyclotron Unit, Hammersmith Hospital, Du Cane

Road, London, W12 0RS, UK D J Brooks

Correspondence to: Dr L H Goldstein Department of Psychology, Department of Psychology,
Institute of Psychiatry, De Crespigny Park, London, SE5 8AF, UK.

RE5 8AF, UK. and in final revised form 22 January 1997

Accepted 23 January 1997

\begin{abstract}
Objectives-To examine the relation between cognitive dysfunction and pseudobulbar features in patients with amyotrophic lateral sclerosis (ALS).

Methods-The performance of two patient groups, ALS with pseudobulbar palsy $(n=24)$ and ALS without pseudobulbar palsy $(n=28)$, was compared with 28 healthy age matched controls on an extensive neuropsychological battery. Tests used were the national adult reading test, short form of the WAIS-R, recognition memory test, Kendrick object learning test, paired associate learning, Wisconsin card sorting test, verbal fluency, Stroop and negative priming tests, a random movement joystick test, and a computerised Tower of Hanoi test.
\end{abstract}

Results-Tests of executive function showed a pronounced deficit on written verbal fluency in both ALS groups in comparison to controls, which tended to be more prominent in patients with ALS with pseudobulbar palsy. The random movement joystick test (a non-verbal test of intrinsic movement generation) showed an impairment in the generation of random sequences in patients with pseudobulbar palsy only. The computerised Tower of Hanoi showed a subtle planning impairment (shorter planning times) in all the patients with ALS compared with controls on trials requiring more complex solutions. In addition the pseudobulbar patients displayed shorter planning times on complex trials, and tended to solve these trials less accurately. There was also evidence of a deficit for all patients with ALS in comparison with controls on total errors and number of categories achieved on the Wisconsin card sorting test and a strong tendency towards an impairment on a task of selective attention and cognitive inhibition (negative priming). A word recognition memory deficit was showed across both ALS groups.

Conclusions-This study elicited cognitive deficits (involving predominantly executive processes, with some evidence of memory impairment) in patients with ALS and further strengthened the link between ALS and frontal lobe dysfunction, this being more prominent in patients with pseudobulbar palsy. However, cognitive impairments sugges- tive of extramotor cortical involvement were not exclusive to this subgroup.

$(\Im$ Neurol Neurosurg Psychiatry 1997;62:464-472)

Keywords: amyotrophic lateral sclerosis; pseudobulbar palsy; neuropsychological impairment; executive dysfunction

Amyotrophic lateral sclerosis (ALS), is characterised by degeneration of the corticospinal tract, brainstem, and spinal motor neurons. However, the selective vulnerability of motor neurons in patients with ALS is relative and in recent studies it has been evident that in nondemented patients with ALS abnormalities of extramotor areas (particularly frontal and temporal) are common. ${ }^{1-11}$ In our PET activation studies, ${ }^{78}$ patients with ALS showed less activation of several prefrontal and limbic regions. These abnormalities were particularly evident in patients who were impaired on a task of written verbal fluency. ${ }^{7811}$ Taken together with findings of selective cognitive impairments ${ }^{1-6}$ ALS may be seen as a multisystem disorder in which involvement of extramotor cortex is an integral feature.

The question arises as to whether abnormalities of cognitive function and prefrontal and limbic changes detected on functional brain imaging studies are indicators of a subgroup of patients with ALS. Indeed patients with only lower motor neuron involvement were less impaired on a range of frontal lobe and memory tests than those with upper motor neuron involvement ${ }^{12}$ and David and Gillham $^{3}$ suggested that cognitive impairment was likely to be seen in patients with established disease and corticobulbar neuronal damage (pseudobulbar palsy)

The purpose of this investigation was to examine the profile of cognitive impairments in patients with ALS and to explore whether such deficits are related to the presence of pseudobulbar palsy. Patients with ALS were tested using a combination of experimental and standard tests of executive and memory function, previously found to be sensitive to ALS, as well as more experimental procedures of executive function, which provide measures of planning, intrinsic generation, and attention. The cognitive profiles of patients with ALS with or without clinical evidence of corticobulbar neuronal damage, and healthy matched control subjects were compared to determine whether cognitive dysfunction was 
exclusive to patients with ALS with pseudobulbar palsy.

\section{Materials and methods SUBJECTS}

Patients with ALS

Fifty two patients ( 37 male, 15 female) with ALS were recruited from the King's MND Care and Research Centre and tested between 1993 and 1995. All had clinical and electrophysiological evidence of combined upper and lower motor neuron involvement in at least one region. The patients were subdivided into those with pseudobulbar palsy $(n=24)$, and those without pseudobulbar palsy $(n=28)$. Pseudobulbar palsy was defined as clinical evidence of upper motor neuron involvement in musculature innervated by the pontine and medullary cranial motor nuclei, (hyperactive jaw and facial reflexes, a snout response, and spastic dysarthria). No patient had a history of cerebrovascular disease (including ischaemia), hypertension, or diabetes and none were taking psychoactive drugs. Neurological data were taken from the records of the patients' clinic visits nearest to the time of testing.

Healthy controls

Twenty eight age matched healthy controls (16 men, 12 women) were also tested. They were recruited from a local education centre, or were friends or spouses of patients with ALS recruited through the local Motor Neurone Disease Association branch.

\section{STATISTICAL DESIGN}

A one way analysis of variance (ANOVA), with one between subjects group factor, was used to compare all three subject groups. Two specified independent contrasts were employed; a first comparing all patients with ALS with controls, and a second comparing the two patient groups. For the analysis of neuropsychological tests in which repeated measures were taken across conditions an ANOVA was conducted with one between subjects group factor comparing all three subject groups (with specified contrasts as above), using a repeated measures factor involving up to four variables. Correlational analyses were conducted using Spearman's rank order correlation on data which was not normally distributed. Significance was determined for $\mathrm{p}<0.05$, and precise values are given in the relevant tables.

\section{NEUROPSYCHOLOGICAL ASSESSMENT}

Standard and experimental procedures, focusing on executive and memory functions, were adapted for patients with a range of disabilities, including upper limb and speech impairments, but the diversity of functional disability found in patients with ALS prevented all of the neuropsychological tests from being conducted on all patients. Anxiety and depression were measured using the hospital anxiety and depression scale (HAD), ${ }^{12}$ to exclude the possibility that abnormal cognitive profiles may be related to high levels of such emotional fac- tors. The depression scale was currently modified for use with both patients and controls, with the removal of one statement "I feel as if I am slowed down". It was considered that responses to this statement falsely exaggerated the measure of depression, due to the severity of physical disability in some of the patients with ALS.

\section{Intelligence}

Intellectual ability was assessed using the national adult reading test-revised ${ }^{13}$ (NART), to estimate premorbid full scale IQ and a short form of the WAIS-R, ${ }^{14}$ using vocabulary, similarities, and comprehension subtests to give a prorated measure of current verbal IQ (VIQ). ${ }^{15}$

\section{Memory}

Memory tests included the verbal paired associate learning ${ }^{16}$ test (PAL) the recognition memory test ${ }^{17}$ (RMT) for words and faces, and the Kendrick object learning test $^{18}$ (KOLT). In the KOLT age scaled normative data are only available for subjects over 55 years old, so raw and age scaled scores were considered.

\section{Executive functions}

Assessment of executive functions was conducted using various tests. Thurstone's written verbal fluency test ${ }^{19}$ was used, in which subjects are required to write as many words as possible beginning with a given letter. A written (rather than spoken) verbal fluency task was employed to permit measurement of executive dysfunction in patients with severe bulbar involvement. The task was modified to control for speed of writing, and hence allow meaningful assessment of patients with upper limb and consequent writing disabilities. This was achieved by using a copy condition later during testing, after a rest from motor tasks, where the subject was timed as they copied the words they had written previously. This writing control condition enabled the calculation of a verbal fluency index (VFI), which provided an estimate of the average time taken to think of each word ((time allowed for testtime to copy words)/total number of words produced). The battery also included a computerised full version of the Wisconsin card sorting test ${ }^{20}$ which examines rule deduction and set shifting.

The random movement joystick task $^{21}$ involves the generation of movements using a four way directional joystick. In the "free selection" experimental condition the subject was required to move the joystick in one of four directions (up, down, left, and right) on the presentation of a tone. In a slight variation on previous versions, ${ }^{21}$ the subject watched a computer monitor, on which there was a graphic representation of the four directions. The subject was instructed to complete 50 moves with the joystick, and was told that the choice of direction should be random and sequences of movements had to be avoided. A second, "fixed" control condition involved moving the joystick on the presentation of a 
tone, but the direction of the movement was specified by the computer display. A comparison of times taken to move the joystick between the two conditions provided a measure of decision time-that is, time taken to generate random choices (time to choose a random direction-time to select specified direction). The task also produced measures of "randomness" of intrinsic generation, which were calculated by observing the sequence of 50 moves completed by the subject, and comparing their frequency of occurrence to that predicted by a completely random set.

The computerised Tower of Hanoi task used to measure executive functions of planning and working memory, was based closely on the three dimensional computerised Tower of London test. ${ }^{22}{ }^{23}$ The test consists of a representation of three discs, slotted onto three rods, displayed on a touch sensitive screen. Two arrangements of discs were presented on the screen, a goal arrangement (top) and a response arrangement (bottom). Unlike the computerised Tower of London test, the discs here are all the same colour, but differ in size. In the problem solving condition, the subject has to rearrange the three discs, moving one at a time, to reach a goal arrangement, in as few moves as possible. Subjects were presented with consecutive arrangements which could be solved in a minimum of three, four, five, and six moves (four trials of each). In half of these trials, on the first move, subjects were required to move a disc to a position which was spatially distal from that specified in the goal arrangement, to finish in the minimum number of moves. These were termed complex trials, and contrasted with the remaining presentations, termed simple trials. Differences in speed of movement between subjects were controlled by using a motor control condition, in which the same arrangements were presented as in the problem solving condition, but the discs to be moved were specified by the computer (so removing the element of choice). A comparison of speed of response between the problem solving and motor control conditions provided a measure of planning time (time taken to compute the first move). A third, working memory condition, was also employed and consisted of the presentation of a sequence of moves of the discs which the subject was required to subsequently reproduce by pointing to the discs on the screen, in a manner similar to the other conditions.

Lastly a computerised test of attention and inhibition was also administered which tested the presence of Stroop and negative priming effects. ${ }^{24}$ The test procedure consisted of three conditions: control, Stroop, and negative priming. Throughout the test the subject was required to name the ink colour of the presented stimulus (either a row of $\mathrm{Xs}$, or a colour name word) as quickly as possible, while ignoring the actual stimulus. In the control condition the stimulus consisted of a row of Xs. In the Stroop condition the stimulus consisted of a colour word which was unrelated to the target ink colour (for example,
RED printed in blue ink). In the negative priming condition, the stimulus also consisted of a colour word; however, the ignored word shown on the previous presentation predicted the subsequent target ink colour. Performance was measured in terms of reaction times (measured by a voice activated relay connected to the computer) and number of errors for each condition. A comparison of performance on the Stroop and control conditions provides measures of the Stroop effect, in which normal subjects show a delayed response of ink colour naming, due to interference of competing responses (reading the word, naming the colour ink). A comparison of the negative priming and Stroop conditions provides measures of the negative priming effect in which normal subjects display a further increase in response latency when asked to name a target which has been previously ignored as a distractor.

\section{Results}

\section{SUBJECT CHARACTERISTICS}

There was no overall difference between groups in patients' ages. However, a contrast comparing the two patient groups showed that the patients with ALS with pseudobulbar palsy were significantly younger than those without pseudobulbar palsy. The combined ALS patient group was not, however, significantly younger than controls. The possible effect of age on test performance was removed from further analysis of neuropsychological results in which age was found to correlate with test scores-that is, for the Wisconsin card sorting test, computerised Tower of Hanoi, PAL, and KOLT results-by using age as a covariate. For all of these measures a test of homogeneity of variance was conducted with age, and found not to be significant, permitting the use of age as a covariate. There were no significant differences between groups on the age at which the subjects left education (school leaving age + years in further education). Analysis of the differences in duration of disease between the two patient groups was significant with the patients with ALS without pseudobulbar palsy displaying a longer duration of illness than those with pseudobulbar palsy. This difference reflects the nature of ALS, in which presence of bulbar symptoms reflects poor prognosis. ${ }^{25}$ Duration of illness did not correlate significantly with any test results and so was not removed further from the analysis as a covariate measure. Disability was measured using the ALS severity scale, ${ }^{26}$ which provides separate measures for bulbar and spinal functions (table 1). The groups differed significantly on scores of bulbar function (speech and swallowing), in accordance with the subdivision of patients. However, there was no significant difference between patient groups on scores of spinal (upper and lower limb) function. Overall there was a significant difference between patient groups in total disability scores, with the patients with ALS with pseudobulbar palsy displaying greater disability, due to the severity of bulbar involvement. 
Table 1 Subject characteristics, means (SD), and exact $P$ values for analyses between groups

\begin{tabular}{|c|c|c|c|c|c|c|}
\hline & $\begin{array}{l}\text { ALS with } \\
\text { pseudobulbar } \\
\text { palsy } \\
(n=24)\end{array}$ & $\begin{array}{l}\text { ALS without } \\
\text { pseudobulbar } \\
\text { palsy } \\
(n=28)\end{array}$ & $\begin{array}{l}\text { Controls } \\
(n=28)\end{array}$ & $\begin{array}{l}\text { Comparison } \\
\text { between } \\
\text { three groups } \\
\text { (P value) }\end{array}$ & $\begin{array}{l}\text { ALS v } \\
\text { Controls } \\
\text { (P value) }\end{array}$ & $\begin{array}{l}\text { ALS with } \\
\text { pseudobulbar } \\
\text { palsy v } \\
\text { ALS without } \\
\text { pseudobulbar } \\
\text { palsy } \\
\text { (P value) }\end{array}$ \\
\hline $\begin{array}{l}\text { Age (y) } \\
\text { Education (leaving age, y) } \\
\text { Duration (months) }\end{array}$ & $\begin{array}{l}53 \cdot 4(11 \cdot 6) \\
17 \cdot 4(2 \cdot 9) \\
17 \cdot 9(6 \cdot 80\end{array}$ & $\begin{array}{l}60 \cdot 4(11 \cdot 1) \\
17 \cdot 3(2 \cdot 7) \\
26 \cdot 0(14 \cdot 3)\end{array}$ & $\begin{array}{l}58 \cdot 3(12 \cdot 6) \\
17 \cdot 4(2 \cdot 7) \\
\text { NA }\end{array}$ & $\begin{array}{l}0 \cdot 105 \\
0.918 \\
\text { NA }\end{array}$ & $\begin{array}{l}0.624 \\
0.924 \\
\text { NA }\end{array}$ & $\begin{array}{l}0.038 \\
0 \cdot 828 \\
0.012\end{array}$ \\
\hline $\begin{array}{l}\text { Bulbar function: } \\
\text { Speech } \\
\text { Swallowing }\end{array}$ & $\begin{array}{l}7 \cdot 0(2 \cdot 2) \\
8 \cdot 2(1 \cdot 6)\end{array}$ & $\begin{array}{l}9 \cdot 4(1 \cdot 7) \\
9 \cdot 6(1 \cdot 1)\end{array}$ & $\begin{array}{l}\text { NA } \\
\text { NA }\end{array}$ & $\begin{array}{l}0.001 \\
0.001\end{array}$ & $\begin{array}{l}\text { NA } \\
\text { NA }\end{array}$ & $\begin{array}{l}\text { NA } \\
\text { NA }\end{array}$ \\
\hline $\begin{array}{l}\text { Spinal function: } \\
\text { Upper limb } \\
\text { Lower limb } \\
\text { Total disability score } \\
\text { HAD anxiety } \\
\text { HAD depression } \\
\text { NART FIQ } \\
\text { VERBAL IQ }\end{array}$ & $\begin{array}{c}7 \cdot 4(2 \cdot 2) \\
7 \cdot 4(2 \cdot 1) \\
30.0(4 \cdot 5) \\
7 \cdot 1(4 \cdot 3) \\
3.0(2 \cdot 3) \\
111.0(14 \cdot 0) \\
111.7(14 \cdot 3)\end{array}$ & $\begin{array}{r}7 \cdot 6(2 \cdot 2) \\
6 \cdot 8(2 \cdot 0) \\
33 \cdot 3(4 \cdot 6) \\
6.6(3 \cdot 3) \\
2.9(2 \cdot 4) \\
111 \cdot 2(13 \cdot 1) \\
119.3(13 \cdot 3)\end{array}$ & $\begin{array}{l}\text { NA } \\
\text { NA } \\
\text { NA } \\
5 \cdot 5(3 \cdot 2) \\
2 \cdot 6(2 \cdot 6) \\
114 \cdot 0(8 \cdot 3) \\
117 \cdot 0(8 \cdot 7)\end{array}$ & $\begin{array}{l}0 \cdot 745 \\
0 \cdot 279 \\
0 \cdot 012 \\
0 \cdot 261 \\
0 \cdot 874 \\
0 \cdot 123 \\
0 \cdot 093\end{array}$ & $\begin{array}{l}\text { NA } \\
\text { NA } \\
\text { NA } \\
0 \cdot 110 \\
0 \cdot 605 \\
0 \cdot 084 \\
0.596\end{array}$ & $\begin{array}{l}\text { NA } \\
\text { NA } \\
\text { NA } \\
0 \cdot 661 \\
0 \cdot 968 \\
0 \cdot 219 \\
0.032\end{array}$ \\
\hline
\end{tabular}

Disability scores (bulbar and spinal functions and total disability) are taken from the ALS severity scale (Hillel et al ${ }^{26}$ ); low scores Disability scores (bulbar and spinal functions and total disability) are taken from the ALS severity scale (Hillel $e t$ al ${ }^{26}$ ); low scores
represent functional impairment (maximum = 10); duration of illness = time (months) between onset of symptoms and testing; represent functional impairment $(\operatorname{maximum}=10)$; duration of illness $=$ time $($ mo
education $=$ school leaving age + years in further education; NA $=$ not applicable.

A comparison of the HAD anxiety and modified depression scores showed no evidence of a significant difference between groups. This suggests that impairments on the neuropsychological measures reported below are not a result of differences in the degree of anxiety and depression between groups.

NEUROPSYCHOLOGICAL TESTS

Measures of intellectual functioning

On measures of intelligence, the NART predicted full scale IQ (FIQ) scores showed no significant differences in the overall analysis between the three groups (table 1). The specified contrasts, however, showed a trend towards a significant difference between all patients with ALS and controls. This suggests that the two patient groups together had slightly (but not significantly) lower predicted premorbid FIQ scores. A comparison of current VIQ scores (table 1) showed only a weak trend towards a significant difference between the three groups, but the results of the specified contrasts showed that the pseudobulbar palsy group displayed lower VIQ scores than the patients with ALS without pseudobulbar palsy.

The NART and WAIS-R subtests both require verbal responses; hence to test whether differences in performance were related to severity of speech impairments, a correlational analysis was conducted between IQ measures and scores of speech (bulbar) function (table
1) in the patient groups. The NART scores did not significantly correlate with speech function $(r=0 \cdot 20, \mathrm{P}>0 \cdot 15)$, but a significant correlation emerged between speech and WAIS-R VIQ measures $(r=0.36, \mathrm{P}<$ $0.025)$. The NART involves reading aloud single words, whereas the WAIS-R subtests require elaborate spoken responses. Hence the difference between the two patient groups in VIQ seems to be related to the severity of dysarthria in the patients with pseudobulbar palsy, which probably resulted in them offering shorter responses to questions. As the NART FIQ scores did not correlate with functional bulbar impairments, and the comparison between groups suggested reduced scores in the patients with ALS, the effect of this measure was removed from the further analysis of neuropsychological scores, when necessary. Hence the NART FIQ was employed as a covariate in the analysis of scores which correlated significantly with NART performancethat is, PAL, RMT for words, VFI, and decision times of the random movement joystick test. Tests of homogeneity of variance with the NART FIQ scores were conducted, none of which was found to be significant.

\section{Memory (table 2)}

Tests of memory showed no evidence of a deficit in the patient groups in the PAL test, for the learning of "easy", semantically related word pairs, although there was a slight ten-

Table 2 Memory test scores, means (SD)

\begin{tabular}{|c|c|c|c|c|c|c|}
\hline Test & $\begin{array}{l}\text { ALS with } \\
\text { pseudobulbar } \\
\text { palsy } \\
(\text { mean }(S D) n)\end{array}$ & $\begin{array}{l}\text { ALS without } \\
\text { pseudobulbar } \\
\text { palsy } \\
(\text { mean }(S D) n)\end{array}$ & $\begin{array}{l}\text { Controls } \\
\text { (mean (SD) n) }\end{array}$ & $\begin{array}{l}\text { Comparison } \\
\text { between } \\
\text { three groups } \\
(P \text { value })\end{array}$ & $\begin{array}{l}\text { ALS v } \\
\text { control } \\
(P \text { value) }\end{array}$ & $\begin{array}{l}\text { ALS with } \\
\text { pseudobulbar } \\
\text { palsy v } \\
\text { ALS without } \\
\text { pseudobulbar } \\
\text { palsy } \\
\text { (P value) }\end{array}$ \\
\hline \multicolumn{7}{|l|}{ PAL: } \\
\hline Easy & $11 \cdot 0(1 \cdot 5) 22$ & $11.0(1.6) 28$ & $11.8(2.8) 28$ & 0.354 & $0 \cdot 157$ & 0.968 \\
\hline Hard & $5.4(3.8) 22$ & $6 \cdot 1(2 \cdot 6) 28$ & $6.9(3.1) 28$ & 0.127 & $0 \cdot 178$ & 0.099 \\
\hline Total & $16 \cdot 4(4.9) 22$ & $17 \cdot 2(3 \cdot 3) 28$ & $17.8(3.5) 28$ & 0.267 & 0.330 & $0 \cdot 158$ \\
\hline \multicolumn{7}{|l|}{ RMT: } \\
\hline Words AS & $11.5(2.7) 19$ & $11.7(2.9) 20$ & $13.3(1.4) 22$ & 0.091 & 0.035 & 0.391 \\
\hline Faces AS & $10.4(3.2) 19$ & $9 \cdot 6(4 \cdot 3) 20$ & $10 \cdot 7(4 \cdot 1) 22$ & 0.482 & 0.511 & 0.343 \\
\hline \multicolumn{7}{|l|}{ KOLT: } \\
\hline Total & $46.6(9 \cdot 6) 24$ & $45.5(8 \cdot 2) 28$ & $46.9(6.5) 28$ & 0.563 & $0 \cdot 409$ & 0.468 \\
\hline ÄS Score & $104 \cdot 2(17 \cdot 6) 11$ & $104.9(14 \cdot 2) 20$ & $109 \cdot 1(10 \cdot 1) 18$ & 0.622 & 0.377 & 0.821 \\
\hline
\end{tabular}

PAL = paired associate learning; RMT = recognition memory test; AS = age scaled scores; KOLT = Kendrick object learning test. 
dency for the patients with pseudobulbar palsy to do worse than the patients with ALS without pseudobulbar palsy on the "hard" pairs. On the RMT (words), the analysis of the age scaled scores showed a significant group effect. In addition, the patients with ALS were overall significantly impaired on word recognition relative to controls. There was no evidence of a significant difference in word recognition scores between the two patient groups. The performance of the patient groups on the RMT for faces showed no deficits. For the KOLT, using the total number of objects recalled (so as to be able to inspect all subjects' data) and age scaled scores (for subjects aged 55 and above) also showed no significant differences between groups. The tests of memory therefore showed only minor impairment, restricted to word recognition, which was evident across patients with ALS.

\section{Executive functions}

Verbal fluency-(table 3) Executive functions as assessed by the written verbal fluency test showed a significant difference in VFI scores between the three subject groups. In addition the combined patient group was significantly impaired relative to controls. There was also a strong trend towards a significant difference between the two patient groups, with the patients with ALS with pseudobulbar palsy taking longer to generate words. To examine whether the modified writing control condition and subsequent calculation of the verbal fluency index prevented a performance decrement resulting from writing disabilities, a correlational analyses was conducted on VFI scores and measures of functional impairment (table 1). The VFI scores did not significantly correlate with severity of upper limb dysfunc- tion, suggesting that speed of writing did not affect this measure. However, a significant correlation emerged between VFI scores and degree of speech impairment (table 1; $r=-0.4, \mathrm{P}<0.025)$.

Wisconsin card sorting test-Performance on this test is measured in terms of four scores (table 3). The patients with ALS overall achieved fewer categories than the controls and made more errors, but there were no between group differences on trials taken to reach to first criterion or \% preservative errors (in which the subject continues to use a previous and currently incorrect rule).

Random movement joystick task-Performance on this test is measured in terms of "randomness coefficients", which are expressed as an "information statistic" ( $i$, for strings of one, two three, and four moves. ${ }^{27}$ Table 3 shows the mean overall $i$ values for each subject group (low coefficients reflect less random sequence generation). Analysis of the $i$ values showed a trend towards a significant group effect and significantly poorer performance by the patients with ALS with pseudobulbar palsy in comparison with those without pseudobulbar palsy. By contrast the analysis of the decision times showed no significant differences between the three groups, despite a decrement in performance.

Computerised Tower of Hanoi-Performance was measured for complex and simple trials separately and analysis was conducted with one between subjects group factor and a repeated measures factor of difficulty level. The second was defined as the minimum number of moves (three, four, five, and six) needed to solve the problem. Planning time consisted of the time between presentation of the array and initial response (problem solv-

Table 3 Executive test scores, means (SDs)

\begin{tabular}{|c|c|c|c|c|c|c|}
\hline Test & $\begin{array}{l}\text { ALS with } \\
\text { pseudobulbar } \\
\text { palsy } \\
(\text { mean }(S D) n)\end{array}$ & $\begin{array}{l}\text { ALS without } \\
\text { pseudobulbar } \\
\text { palsy } \\
(\text { mean }(S D) n)\end{array}$ & $\begin{array}{l}\text { Controls } \\
(\text { mean }(S D) n)\end{array}$ & $\begin{array}{l}\text { Comparison } \\
\text { between } \\
\text { three groups } \\
\text { (P value) }\end{array}$ & $\begin{array}{l}\text { ALS v } \\
\text { control } \\
\text { (P value) }\end{array}$ & $\begin{array}{l}\text { ALS with } \\
\text { pseudobulbar } \\
\text { palsy v } \\
\text { ALS without } \\
\text { pseudobulbar } \\
\text { palsy } \\
\text { (P value) }\end{array}$ \\
\hline $\begin{array}{l}\text { Verbal fluency } \\
\text { index (s) } \\
\text { Wisconsin card } \\
\text { sorting test: }\end{array}$ & $11 \cdot 8(10 \cdot 2) 20$ & $6 \cdot 2(2 \cdot 9) 23$ & $4.9(2 \cdot 7) 28$ & 0.024 & 0.030 & 0.054 \\
\hline $\begin{array}{l}\text { Cat } \\
\text { Total errors } \\
(\%) \text { P errors } \\
\text { Trials to } 1 \text { st }\end{array}$ & $\begin{array}{c}4.5(1.9) 23 \\
37 \cdot 6(24 \cdot 0) 23 \\
16 \cdot 2(10 \cdot 0) 23 \\
17 \cdot 2(14.4) 23\end{array}$ & $\begin{array}{l}4 \cdot 3(1 \cdot 3) 27 \\
37 \cdot 9(20 \cdot 1) 27 \\
16 \cdot 4(8 \cdot 6) 27 \\
22 \cdot 4(22 \cdot 1) 27\end{array}$ & $\begin{array}{c}5 \cdot 0(1 \cdot 3) 28 \\
29 \cdot 9(17 \cdot 8) 28 \\
15 \cdot 8(10 \cdot 3) 28 \\
15 \cdot 8(7 \cdot 9) 28\end{array}$ & $\begin{array}{l}0 \cdot 115 \\
0 \cdot 060 \\
0 \cdot 7006 \\
0 \cdot 346\end{array}$ & $\begin{array}{l}0 \cdot 049 \\
0 \cdot 032 \\
0 \cdot 675 \\
0 \cdot 262\end{array}$ & $\begin{array}{l}0.434 \\
0 \cdot 250 \\
0.459 \\
0.389\end{array}$ \\
\hline $\begin{array}{l}\text { Random movement } \\
\text { joystick test: }\end{array}$ & & & & & & \\
\hline $\begin{array}{l}\text { Decision time } \\
\text { i Statistic }\end{array}$ & $0.26(0.33) 13$ & $0 \cdot 29(0.36) 14$ & $0 \cdot 21(0.25) 26$ & $0 \cdot 801$ & $0 \cdot 806$ & $0 \cdot 558$ \\
\hline $\begin{array}{l}\text { (four moves) } \\
\text { Computerised Tower } \\
\text { of Hanoi: } \\
\text { CT-TS: }\end{array}$ & $0.418(0.135) 13$ & $0.495(0.092) 14$ & $0.452(0.089) 26$ & $0 \cdot 060$ & $0 \cdot 191$ & $0 \cdot 042$ \\
\hline $\begin{array}{c}4 \\
5 \\
6 \\
\text { ST-TS: }\end{array}$ & $\begin{array}{l}1.3(0.7) 19 \\
0.9(0.8) 19 \\
0.8(0.9) 19\end{array}$ & $\begin{array}{l}1.4(0.6) 24 \\
1.3(0.8) 24 \\
0.9(0.8) 24\end{array}$ & $\begin{array}{l}1.6(0.6) 26 \\
1.2(0.7) 26 \\
1.0(0.8) 26\end{array}$ & 0.066 & $0 \cdot 107$ & 0.063 \\
\hline $\begin{array}{l}4 \\
5 \\
6\end{array}$ & $\begin{array}{l}1.9(0.3) 19 \\
1.2(0.6) 19 \\
1.5(0.6) 19\end{array}$ & $\begin{array}{l}1 \cdot 7(0 \cdot 6) 24 \\
1 \cdot 1(0 \cdot 7) 24 \\
1 \cdot 0(0 \cdot 7) 24\end{array}$ & $\begin{array}{l}1 \cdot 8(0 \cdot 4) 26 \\
1 \cdot 3(0 \cdot 7) 26 \\
1 \cdot 1(0 \cdot 7) 26\end{array}$ & 0.383 & $0 \cdot 835$ & $0 \cdot 181$ \\
\hline Stroop errors & $1 \cdot 1(2 \cdot 7) 11$ & $1.9(3 \cdot 1) 24$ & $1 \cdot 3(2 \cdot 8) 23$ & 0.678 & 0.752 & $0 \cdot 472$ \\
\hline $\begin{array}{l}\text { RT } \\
\text { NP errors }\end{array}$ & $\begin{array}{l}0 \cdot 19(0.13) 11 \\
1 \cdot 3(3 \cdot 3) 11\end{array}$ & $\begin{array}{c}0.36(0.10) 24 \\
-0.2(3.7) 24\end{array}$ & $\begin{array}{l}0 \cdot 15(0 \cdot 15) 23 \\
0.5(3 \cdot 2) 23\end{array}$ & $\begin{array}{l}0.508 \\
0.494\end{array}$ & $\begin{array}{l}0.247 \\
0.901\end{array}$ & $\begin{array}{l}0.779 \\
0.242\end{array}$ \\
\hline RT & $0.01(0.12) 11$ & $-0.2(0.09) 24$ & $0.05(0.09) 23$ & 0.062 & 0.051 & 0.402 \\
\hline
\end{tabular}

Verbal fluency index = average time (seconds) taken to generate each word; Cat $=$ categories (maximum of 6); (\%) P errors $=$ percentage perseverative errors; Trials to $1 \mathrm{st}=$ number of trials taken to achieve first of six categories; ST = simple trials; CT = complex trials; TS $=$ trials solver
effect; RT $=$ reaction time(s). 
Computerised Tower of Hanoi, mean planning times for complex (above) and simple (below) trials.

Difficulty level reflects minimum number of moves required to solve problem. $\mathbf{\square}=A L S$ with pseudobulbar palsy; $\square=$ ALS without pseudobulbar palsy; $+=$ controls.

Analysis of complex trials: between groups $P=$ $0 \cdot 0248 ; A L S$ v controls $P=0.0391 ; A L S$ with pseudobulbar palsy $v$ ALS without pseudobulbar palsy $P=0.045$. Analysis of simple trials: between groups $P=0 \cdot 126 ; A L S$ v controls $P=0.237 ; A L S$ with pseudobulbar palsy $v$ ALS without pseudobulbar palsy $P=0.077$.
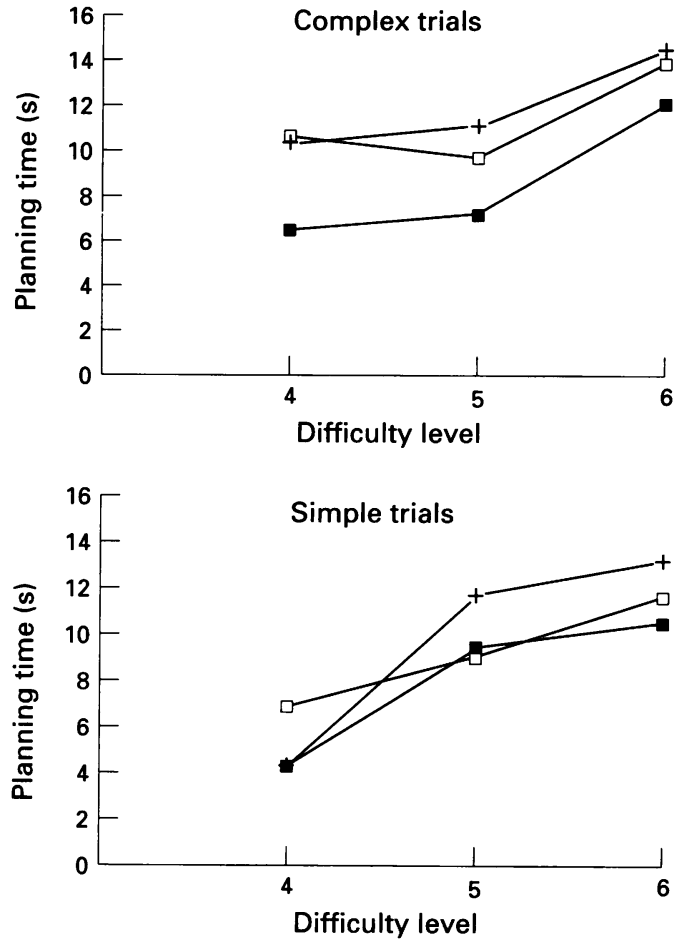

ing-motor control condition). The figure gives the mean planning times (and exact $P$ values) for the three subject groups across levels represented for complex and simple trials. For subsequent analysis these data were transformed logarithmically. In the analysis of planning times for complex trials, the overall comparison of the three subject groups showed a significant group effect, a significant difference between the combined ALS patient group compared with controls, and a significant difference between the two patient groups. In addition there was also a significant effect of difficulty level $(F=8 \cdot 15, \mathrm{df}=$ $2,132, P<0.001)$. The figure shows that across the complex trials the patients with ALS with pseudobulbar palsy used less time planning before responding than did the two other subject groups.

Analysis of the simple trials across the three subject groups was not significant although the patients with pseudobulbar palsy tended to have slightly faster planning times than patients with ALS without pseudobulbar palsy. In addition there was a significant effect of difficulty level $(P=0.016)$. The figure illustrates these findings.

Performance accuracy on the complex trials was measured by the number of trials solved (TS) in the minimum moves required. The analysis of the complex trials showed a trend in the comparison of all three subject groups, and a trend for the patients with ALS with pseudobulbar palsy to solve fewer trials than those without pseudobulbar palsy. Performance on the simple trials did not significantly differ between the three groups. Overall these results disclose that the patients with pseudobulbar palsy displayed shorter planning times on complex trials than controls, with a tendency to fail to solve these trials as effectively. In the working memory condition, analysis was conducted using one between subjects group factor and a repeated measures factor of difficulty level (four levels; two, three, four, and five moves). The ANOVA showed no difference between the three subject groups and there were no significant differences in the subsequent individual comparisons between the ALS patient groups and controls.

Stroop test and negative priming-(table 3) The analysis of the Stroop effect (performance on the Stroop - control conditions) showed no significant differences between groups in mean reaction times, or in the number of errors produced. However, the reaction times for the negative priming effect (performance on negative priming:-Stroop conditions), showed some evidence of an overall effect of group, with a trend towards significance. The combined ALS patient group displayed a strong trend towards a significant impairment in negative priming relative to controls. Inspection of the mean reaction times in table 3 shows that the patient groups displayed less negative priming than controls, with reduced response latencies. However, no differences emerged in the comparison of errors in the priming task.

In summary, the results of the tests of frontal lobe function showed some evidence of executive dysfunction across patients with ALS (but which was more prominent in the patients with ALS with pseudobulbar palsy), in tests of intrinsic response generation (verbal fluency and random movement joystick test), and in planning (computerised Tower of Hanoi).

\section{Discussion}

The findings of this study of 52 patients with ALS showed a pattern of cognitive dysfunction, involving predominantly executive processes, with evidence of a word recognition memory impairment. Executive (frontal lobe) deficits were more pronounced in patients with ALS with pseudobulbar palsy. However, the presence of cognitive impairments was not exclusive to this group.

\section{COGNITIVE IMPAIRMENT IN THE PATIENTS} WITH ALS WITH PSEUDOBULBAR PALSY

The most striking cognitive impairment was shown using the written verbal fluency test. Although the patients with ALS were impaired on this test as a group, the patients with pseudobulbar palsy tended to be more impaired. Here written orthographic determined word generation was modified to control for speed of writing using a copy condition. Although subtle effects of fatigue may have remained, the resulting verbal fluency index did not correlate with severity of upper limb dysfunction. Verbal fluency is dependent on intrinsic response initiation and the results showed that the patients with pseudobulbar palsy tended to require longer thinking times to generate words. Verbal fluency deficits have been the most consistently reproduced finding in neuropsychological investigations of ALS, ${ }^{12578}$ and are suggestive of dysfunction of the left prefrontal cortex. ${ }^{28-32}$ In addition, functional imaging using verbal 
fluency activation paradigms have directly associated the processes involved in word generation, with increases in regional cerebral blood flow (rCBF) in the left dorsolateral prefrontal cortex (DLPFC; Brodmann area 46). ${ }^{33-35}$ Using a verbal fluency PET activation paradigm, dysfunction of this region was seen in patients with ALS with corresponding verbal fluency deficits, in comparison with patients with ALS selected for good verbal fluency and without other cognitive impairment. ${ }^{11}$

The finding of an impairment on the random movement joystick task in ALS, is consistent with our previous results. ${ }^{7}$ In the current study the patients with pseudobulbar palsy displayed evidence of an impairment in the production of random sequences when compared with patients without pseudobulbar palsy. Despite this performance decrement, the three groups were matched in terms of decision times (time taken to choose random direction). The task requires the internal generation of willed movement and is similar to verbal fluency in terms of processes of intrinsic generation, in which responses are not fully specified by the test. ${ }^{33}$ The finding of a deficit on a non-verbal test of intrinsic generation is therefore also in accordance with a report of impairments in patients with ALS on a design fluency test. ${ }^{5}$ The random generation of movements using a joystick has been associated with bilateral activation of the DLPFC. ${ }^{21}$ Hence, impairments in such executive processes are suggestive of dysfunction of the DLPFC, occurring predominantly in patients with ALS with pseudobulbar palsy.

Performance on the computerised Tower of Hanoi test showed evidence of a subtle impairment in planning, in that the patients with pseudobulbar palsy displayed shorter planning times on complex trials. These trials require greater flexibility of initiation of response as the solution is less obvious. On these trials the patients with pseudobulbar palsy tended to plan less exhaustively and seemed to be more "impulsive", which may have resulted in a slight decrement in performance, as shown by the number of trials solved in the minimum number of moves. A single photon emission computed tomography (SPECT) investigation of the related computerised Tower of London test has shown correlations between increased rCBF in the left prefrontal cortex (including the DLPFC), longer planning times, and more efficient performance during the task. ${ }^{36}$ The pattern of performance of the pseudobulbar palsy group would therefore again suggest some evidence of dysfunction of this region. The findings from this test also provided evidence of intact working memory function. This would suggest that the impairments on the above frontal lobe tests are more likely to reflect a dysfunction of other executive processes.

COGNITIVE IMPAIRMENTS IN THE COMBINED ALS PATIENT GROUP

Indications of cognitive performance deficits were also found in the combined ALS patient group, suggesting that some impairments were independent of pseudobulbar involvement. The ALS patient group as a whole was impaired in terms of the number of categories achieved on the Wisconsin card sorting test and the total number of errors made, in broad agreement with David and Gillham. ${ }^{3}$ Large DLPFC lesions have been associated with poor rule shifting. ${ }^{37}$ No deficit was found on the Stroop task, consistent with the findings of previous investigations. ${ }^{58}$ However, in the negative priming condition patients with ALS showed a tendency towards faster reaction times than controls. The healthy controls showed increased response latency in comparison with the ALS group when naming a target which had previously been automatically inhibited. ${ }^{38}$ Such inhibitory mechanisms regulate the processes of selective attention. 3940 Cortical regions suggested to be involved in the processes of response selection and selective attention include the medial prefrontal cortex and the anterior cingulate gyrus. ${ }^{33} 34$ 41-43 These areas have also been shown to be implicated in patients with ALS with cognitive impairment. ${ }^{8}$

Memory dysfunction in the patients with ALS was only found using the recognition memory test for words. This finding contradicts previous studies which have shown unimpaired performance using this measure, ${ }^{68}$ but memory deficits have been elicited using different tests. ${ }^{13}$ In the present study no significant deficits were found on the Kendrick object learning test and paired associate learning test, by contrast with other studies ${ }^{3}$ and variability in findings has been commented upon previously. ${ }^{8}$ The finding of some memory impairments concur with evidence of limbic system involvement as demonstrated by PET. ${ }^{78}$

\section{COGNITIVE IMPAIRMENTS AND}

NEUROPATHOLOGY IN ALS

The predominance of executive dysfunction in the ALS patients with pseudobulbar palsy is strongly supported by Kiernan and Hudson's ${ }^{10}$ MRI investigation, in which quantitative anatomical analysis showed shrinkage in the volume of the underlying white matter, in the anterior frontal cortex of 11 non-demented patients with ALS. A highly significant correlation $(P<0.01)$ existed between this measure of neuronal damage and clinical scores of bulbar function, suggesting that the degree of neuronal degeneration of axons projecting to the frontal cortex is related to the severity of bulbar involvement. Unfortunately no neuropsychological data were reported for these patients. Previous neuropsychological studies have not been designed to permit careful comparison between patients with ALS with or without pseudobulbar palsy. Thus while David and Gillham ${ }^{3}$ concluded that cognitive dysfunction in ALS was associated with corticobulbar neuronal damage, only $25 \%$ of their subjects did not show this neurological picture and their only measure of executive dysfunction was the Wisconsin card sorting test. The present findings suggest that such deficits are 
not specific to the pseudobulbar palsy group. Other studies have not included explicit measures of executive function, ${ }^{4}$ have not explored the relation between extra motor dysfunction and bulbar involvement, ${ }^{25811}$ or have included insufficient numbers of patients with cortcobulbar symptoms for sensible comparisons to be made. ${ }^{3}$

The results of previous neuroimaging investigations, ${ }^{67811}$ showing abnormalities of the frontal lobes, anterior cingulate, thalamus, and parahippocampal gyrus, are consistent with the pattern of cognitive impairment shown here. In addition, the present study suggests a possible relation between executive dysfunction and pseudobulbar palsy and is indicative of more prefrontal involvement (particularly of DLPFC) in this group. In our recent PET investigation, patients who displayed extended cortical involvement encompassing DLPFC with corresponding verbal fluency impairment tended to show a slightly higher incidence of pseudobulbar involvement. ${ }^{11}$

The association between executive dysfunction and pseudobulbar palsy parallels reports of cases of ALS related dementia, in which pseudobulbar palsy is a common feature. Bulbar signs may be present in up to $85 \%$ of cases of dementia ${ }^{44}$ although these are often not distinguished from pseudobulbar symptomatology. The cognitive profile of patients with ALS with dementia is also characterised by behavioural and cognitive problems reflecting gross frontal lobe dysfunction. ${ }^{65-47}$ The relation between pseudobulbar palsy and frontal lobe function may then be common to both ALS related dementia and typical ALS, thus providing support for the existence of a range of extramotor cerebral involvement in ALS. ${ }^{48}$

The relevance of examining subtypes of ALS in the manner undertaken here is highlighted by recent findings that possession of the apolipoprotein $\mathrm{E}$ (APOE) $\varepsilon 4$ allele is associated with bulbar onset ALS, ${ }^{49}$ as well as with earlier onset Alzheimer's disease and dementia in Parkinson's disease. ${ }^{50}$ Defining the characteristics of the phenotypic variations in ALS through cognitive and neuroimaging studies will ultimately help clarify the processes leading to cognitive deterioration in other neurodegenerative diseases. Prospective cognitive studies of patients with ALS with APOE $\varepsilon 4$ allele will throw light on the development of neuropsychological impairment in ALS which can be correlated with neuropsychological, neuroimaging, and ultimately postmortem studies.

This study was supported by the Medical Research Council, UK. The MND Care and Research Centre is supported by the Motor Neurone Disease Association, UK.

1 Gallassi R, Montagna P, Ciardulli C, Lorusso S, Mussoto V, Stracciari A. Cognitive impairments in motor neurone disease. Acta Neurol Scand 1985;71:480-4.

2 Gallassi R, Montagna P, Morriale A, Lorusso S, Tinuper P, Daidone R, Lugaresi E. Neuropsychological, electroencephalogram and brain computed tomography findings in motor neurone disease. Eur Neurol 1989;29;115-20.

3 David A, Gillham RA. Neuropsychological study of motor neurone disease. Psychosomatics 1986;27:441-5.

4 Iwasaki Y, Kinoshita M, Ikeda K, Takamiya K, Shiojima $T$. Cognitive impairment in amytrophic lateral sclerosis and its relation to motor disabilities. Acta Neurol Scand 1990;
81:141-3.

5 Ludolph AC, Langen KJ, Regard M, Herzog H, Kempo B, Kurwert T. Frontal lobe function in amyotrophic lateral sclerosis: a neuropsychological and positron emission tomography study. Acta Neurol Scand 1992;85:81-9.

6 Talbot PR, Goulding PJ, Lloyd J, Snowden JS, Neary D, Testa HJ. Inter-relation between classic motor neuron disease and frontotemporal dementia: neuropsychological ease and frontotemporal dementia: neuropsychological and single photon emission computed tomog

$7 \mathrm{Kew}$ JM, Leigh PN, Playford ED, Passingham RE, Goldstein LH, Frackowiak RSJ, Brooks DJ. Cortical function in amyotrophic lateral sclerosis: a positron emission tomography study. Brain 1993;116:655-80.

8 Kew JM, Goldstein LH, Leigh PN, et al. The relationship between abnormalities of cognitive function and cerebral activation in amyotrophic lateral sclerosis: a neuropsychological and positron emission tomography study. Brain 1993;116:1399-423.

9 Kato S, Hayashi H, Yagishita A. Involvement of frontotemporal lobe and limbic system in amyotrophic lateral sclerosis: as assessed by serial computed tomography and magnetic resonance imaging. $\mathcal{F}$ Neurol Sci 1993;116:52-8.

10 Kiernan JA, Hudson AJ. Frontal lobe atrophy in motor neuron diseases. Brain 1994;117:747-57.

11 Abrahams S, Kew JJM, Goldstein LH, Brooks DJ, Leigh PN. Frontal lobe function in amyotrophic lateral sclerosis: a positron emission tomography study [abstract]. Ann Neurol 1994;36:273.

12 Zigmond AS, Snaith RP. The hospital anxiety and depression scale. Acta Psychiat Scand 1983;67:361-70.

13 Nelson HE, Willison JR. Restandardisation of the NART against the WAIS-R. Windsor: NFER-Nelson, 1991.

14 Wechsler D. WAIS-R manual. Cleveland, OH: The Psychological Corporation, 1981.

15 Canavan AGM, Dunn G, McMillan TM. Principle components of the WAIS-R. Br F Clin Psychol 1986;25:81-5.

16 Wechsler D. Wechsler memory scale-revised. San Antonio: Psychological Corporation, 1987.

17 Warrington EK. Recognition memory test. Windsor: NFERNelson, 1984.

18 Kendrick D. Cognitive tests for the elderly. Windsor: NFERNelson, 1985.

19 Thurstone LL, Thurstone TG. Primary mental abilities. Chicago, Science Research Associates, 1962.

20 Psychological Assessment Resources. Wisconsin card sorting test: computer version. Florida: Psychological Assessment Resources, 1990

21 Deiber M-P, Passingham RE, Colebatch JG, Friston KJ, Nixon PD, Frackowiak RSJ. Cortical areas and the selection of movement: a study with positron emission tomography. Exp Brain Res 1991;84:393-402.

22 Morris RG, Downes JJ, Sahakian BJ, Evenden JL, Heald A, Robbins TW. Planning and spatial working memory in Parkinson's disease. F Neurol Neurosurg Psychiatry 1988; 51:757-66.

23 Morris RG, Rushe T, Woodruffe PWR, Murray RM. Problem solving in schizophrenia: a specific deficit in planning ability. Schizophr Res 1995;14:235-46.

24 Peters ER, Pickering AD, Hemsley DR. Cognitive inhibition and positive symptomatology in schizotypy. Br $\mathcal{F}$ Clin Psychol 1994;33:33-48.

25 Swash M, Swartz MS. What do we really know about amyotrophic lateral sclerosis. $\mathcal{F}$ Neurol Sci 1992;113:4-16.

26 Hillel AD, Miller RM, Yorkston K, McDonald E, Norris FH, Konikao N. Amyotrophic lateral sclerosis severity scale. Neuroepidemiology 1989;8:142-50.

27 Frith CD, Done DJ. Stereotyped responding by schizophrenic patients on a two-choice guessing task. Psychol Med 1983;13:779-86.

28 Milner B. Hemispheric specialisation scope and limits. In: Schmitt FO, Worden FG, eds. The neurosciences third study. Cambridge, MA: MIT Press, 1974:75-89.

29 Pendelton MG, Heaton RK, Lehman RAW, Hulihan D. Diagnostic utility of the Thurstone word fluency test in neuropsychological evaluation. F Clin Neuropsychol 1982; 4:307-17.

30 Benton AL. Differential behavioural effects in frontal lobe disease. Neuropsychologia 1968;6:53-60.

31 Miller E. Verbal fluency as a function of a measure of verbal intelligence and in relation to different types of cerebral pathology. Br f Clin Psychol 1984;23:53-7.

32 Bornstein RA. Contributions of various neuropsychological measures to detection of frontal lobe impairment. Int $\mathcal{F}$ Clin Neuropsychol 1986;3:18-22.

33 Frith CD, Friston K, Liddle PF, Frackowiak RSJ. Willed action and the prefrontal cortex in man: a study with PET. Proc R Soc Lond B Biol Sci 1991;244:241-6.

34 Frith CD, Friston KJ, Liddle PF, Frackowiak RSJ. A PET study of word finding. Neuropsychologia 1991;29: $1137-48$.

35 Cantor-Graae E, Warkentin S, Granzen G, Risberg J. Frontal lobe challenge: a comparison of activation procedures during rCBF measurements in normal subejcts. Neuropsychiatry, Neuropsychology and Behavioural Neuropsychiatry, Neuropsy

36 Morris RG, Ahmed S, Syed GM, Toone BK. Neural correlates of planning ability: frontal lobe activation during the lates of planning ability: frontal lobe activation during the

37 Milner B. Effects of different brain lesions on card sorting. Arch Neurol 1963;9:90-100.

38 Tipper SP, Cranston $M$. Selective attention and priming: inhibitory and facilitatory effects of ignored primes. $Q \mathcal{F}$ Exp Psychol 1985;37A:591-611. 
39 Frith $C D$. Consciousness, information processing and schizophrenia. Br f Psychiatry 1979;134:225-35.

40 Marcel AJ. Conscious and unconscious perception: an approach to the relations between phenomenal experience 238-300.

41 Mesulam M-M. A cortical network for directed attention and unilateral neglect. Ann Neurol 1981;10:309-25.

42 Peterson SE, Fox PT, Posner MI, Mintum M, Raichle ME Positron emission tomographic studies of the cortical anatomy of single word processing. Nature 1988;331: anatomy

43 Bench CJ, Frith CD, Grasby PM, et al. Investigations of the functional anatomy of attention using the Stroop test. Neuoropsychologia 1993;31:907-22.

$44 \mathrm{Kew}$ JJM, Leigh PN. Dementia with motor neuron disease. In: Rossor M, ed. Balleire's clinical neurology: unusual dementias. London: Bailleire Tindal, $1992611-26$. 45 Neary D, Snowden JS, Mann DMA, Northern B, Boulding
PJ, Macdermott N. Frontal lobe dementia and motor neuron disease. F Neurol Neurosurg Psychiatry 1990;53: 23-32.

46 Kato S, Oda M, Hayashi $H$, Kawato A, Shimizu $T$. Participation of the limbic system and its associated areas in the dementia of amyotrophic lateral sclerosis. $f$ Neurol Sci 1994;126:62-9.

47 Peavy GM, Herzog AG, Rubin NP, Mesulam M-M Neuropsychological aspects of dementia of motor neurone disease: a report of two cases. Neurology 1992;42:1004-8.

48 Leigh PN, Kew JM, Goldstein LH, Brooks DJ. The cerebral lesions in amyotrophic lateral sclerosis: new insights from pathology and functional brain imaging. In: Clifford Rose $\mathrm{F}$, ed. $A L S$-from Charcot to the present and into the

49 Al-Chalabi A, Enayat ZE, Bakker MC, et al. Association of apolipoprotein E E4 allele will bulbar-onset motor neurone disease. Lancet 1996;347:159-60

50 Schneider JA, Gearing M, Robbins RS, de l'Aune W, Mirra SS. Apolipoprotein E genotype in diverse neurodegenerative disorders. Ann Neurol 1995;38:131-5. 